Int. J. Electrochem. Sci., 13 (2018) $6248-6258$

\title{
Electrochemical Analysis of Carbon Steel Corrosion Induced by Chloride and Sulfate Ions in Simulated Concrete Pore Solution
}

\author{
Guojian Liu, Yunsheng Zhang ${ }^{*}$, Meng Wu, Yu Zhang, Bo Pang \\ School of Materials Science and Engineering, Southeast University, Nanjing 211189, China \\ *E-mail: liuguojiande@gmail.com zhangyunsheng2011@163.com
}

doi: $10.20964 / 2018.07 .46$

Received: 2 March 2018 / Accepted: 8 May 2018 / Published: 5 June 2018

\begin{abstract}
In this study, the corrosion process of steel reinforcement induced by chloride and/or sulfate ions was investigated by electrochemical measurements and theoretical analysis. Electrochemical impedance spectroscopy as a powerful and revealing tool was adopted to monitor and interpret the corrosion process with experiment time lapse. Detailed information on the parameters of passive film in different corrosion phases was obtained via the proposed electrochemical equivalent circuit simulation. The results indicated that increasing sulfate ions could initiate corrosion. Furthermore, sulfate showed higher corrosion risk than chloride as per amount of substance of aggressive anions in the simulated concrete pore solution. The presence of both chloride and sulfate ions led to higher corrosion rate than that of the exposed to chloride or sulfate ions alone. The Nyquist curve, Bode modulus, and phase angel format of the EIS data revealed more detailed information regarding each stage of corrosion. The Chi-square $\left(\chi^{2}\right)$ value method was adopted for the verification of the fitted results by the proposed equivalent circuit.
\end{abstract}

Keywords: Carbon steel; Corrosion; Electrochemical analysis; Chloride; Sulfate

\section{FULL TEXT}

(C) 2018 The Authors. Published by ESG (www.electrochemsci.org). This article is an open access article distributed under the terms and conditions of the Creative Commons Attribution license (http://creativecommons.org/licenses/by/4.0/). 